\title{
Isolated and Joint Effects of Tobacco and Alcohol Consumption on Risk of Alzheimer's Disease
}

\author{
Ana M. García ${ }^{\mathrm{a}, \mathrm{b}, *}$, Nieves Ramón-Bou ${ }^{\mathrm{c}}$ and Miquel Porta ${ }^{\mathrm{b}, \mathrm{d}, \mathrm{e}}$ \\ ${ }^{a}$ Department of Preventive Medicine and Public Health, University of Valencia, Spain \\ ${ }^{\mathrm{b}}$ CIBER of Epidemiology and Public Health (CIBERESP), Spain \\ ${ }^{\mathrm{c}}$ Consellería de Sanidad, Generalitat Valenciana, Valencia, Spain \\ ${ }^{\mathrm{d}}$ Institut Municipal d'Investigació Mèdica, Barcelona, Spain \\ e School of Medicine, Universitat Autònoma de Barcelona, Spain
}

Accepted 13 January 2010

\begin{abstract}
The roles of smoking and alcohol on the development of Alzheimer's disease (AD) remain unclear. We performed a case-control study on the effects of both exposures before the age of onset of the disease in the cases (and same reference age for their age-matched controls) on disease risk. Interviews were conducted with population controls $(n=246)$ and relatives of cases $(n=176)$ identified through local Alzheimer's Disease Associations. Logistic regression models were built adjusting by gender, age, residence, education, economic situation, employment, and history of dementia in close relatives. Risk of AD was unaffected by any measure of tobacco consumption. Alcohol consumers showed a lower risk of AD than never consumers (adjusted odds ratio, aOR $=0.53,95 \%$ CI 0.32, 0.88), with differences by gender (women aOR $=0.48,95 \%$ CI 0.27 , 0.84; men $\mathrm{aOR}=0.80,95 \% \mathrm{CI} 0.23,2.80$ ). Mean daily total consumption of alcohol and time consuming alcohol showed increasingly protective dose-response relationships in women. Lower AD risk was observed in alcohol drinkers of both genders who never smoked ( $\mathrm{aOR}=0.37,95 \% \mathrm{CI} 0.21,0.65)$. All these associations were independent of the presence of apolipoprotein E4 allele(s) in the cases. Although the sample was small for some analyses addressing these interactions, our results suggest a protective effect of alcohol consumption, mostly in non-smokers, and the need to consider interactions between tobacco and alcohol consumption, as well as interactions with gender, when assessing the effects of smoking and/or drinking on the risk of AD.
\end{abstract}

Keywords: Alcohol drinking, Alzheimer's disease, apolipoprotein E4, case-control studies, humans, smoking, Spain

\section{INTRODUCTION}

The roles of smoking and alcohol consumption on the development of Alzheimer's disease (AD) remain controversial. Concerning tobacco, initial pooled analyses suggesting a protective effect $[1,2]$ were later challenged by longitudinal and case-control studies finding increased risks [3-7], mostly in current or recent

*Correspondence to: Ana M. García, Department of Preventive Medicine and Public Health, University of Valencia, Facultad de Ciencias Sociales, Avda. Tarongers s/n. 46022 Valencia, Spain. Tel.: +34 96391 1421; Fax: +34 96391 7264; E-mail: anagar@uv.es. smokers. Interaction effects between smoking and the apolipoprotein E4 (ApoE4) allele have been suggested as well. First a protective effect of smoking on AD risk was observed only for ApoE4 carriers [8]; more recently, a significant increase in risk related to smoking was only evident for cases without any ApoE4 allele [4,5,7]. Dose-response relationships between smoking and AD are also elusive; some reports suggest complex nonlinear shapes $[9,10]$, while others found linearly increasing risks [7]. In a prospective study [11], the highest risk of AD was observed for current smokers without any ApoE4 allele (adjusted OR aOR $=4.32,95 \%$ CI 1.28, 14.65), but there was no relationship between 
the magnitude of risk and pack-years smoked. Furthermore, former smokers at baseline with any ApoE4 allele showed decreased risk $(\mathrm{aOR}=0.27,95 \% \mathrm{CI} 0.08$, $0.93)$, and $\mathrm{AD}$ risk decreased as the number of packyears increased $(p=0.02)$. A variety of mechanistic and methodological explanations have been proposed for these opposite findings [12-14]. As it has been suggested, it is clear that analyses must properly consider duration and intensity of smoking, time since quitting, and presence of ApoE4 alleles.

On the other hand, evidence of a potential relationship between alcohol consumption and $\mathrm{AD}$ is even scarcer than for smoking. After first reports found no association $[1,9,10,15]$, more recent results point to a protective effect of alcohol, mostly associated to moderate intakes and to wine consumption [16-18]. But differences according to type of alcohol beverage consumed have not always been observed [19]; and increased risks have also been reported for heavy alcohol consumption [20]. Analyses of interactions between alcohol consumption and ApoE4 alleles are scant and conflicting [18,19]. Additionally, interactive effects of smoking and drinking have been observed, and they are supported by the fact that both alcohol and tobacco affect brain nicotinic cholinergic receptors. Smokers and drinkers tended to show lower risks of $\mathrm{AD}$ than subjects who were just smokers or just drinkers [21]. But antagonistic effects of tobacco and wine consumption have also been suggested for some dimensions of general cognitive decline [16].

We carried out a case-control study focused on occupational exposures as potential risk factors for AD. Detailed information on life-long tobacco and alcohol consumption was collected. In this report, we present results on the relationships between alcohol and tobacco consumption and $\mathrm{AD}$ risk, with special attention to controversial issues such as the influence of period, time and intensity of consumption before the age of disease onset, interactions with ApoE4, type of alcoholic beverages consumed, and joint effects of alcohol and tobacco.

\section{MATERIALS AND METHODS}

\section{Design and selection of subjects}

The protocol of the study was approved by the Ethical Committee of the University of Valencia (Spain). Cases were identified through local Alzheimer's Disease Associations (ADAs) in five towns of the region of
Valencia (Valencia city, Alicante, Elda, Villena, and Alcoy). These locations were selected because of proximity and accessibility. ADAs are very common in Spain, having premises in almost all medium and big sized municipalities and with thousands of members, including AD patients and their relatives [22]. Local ADAs are mostly intended to give support, training, and information to patients and caregivers. A medical diagnosis of $\mathrm{AD}$ is required for registration in an $\mathrm{ADA}$, but medical histories of the patients were not accessible. All information regarding diagnosis, age of onset of the disease (age when the disease was first diagnosed), and symptoms of the disease was then obtained through personal interviews with caregivers.

To recruit cases, relatives or caregivers responsible for the $\mathrm{AD}$ patients registered in participating ADAs were randomly selected from available registries and invited by mail to participate in the study, introduced as a research on characteristics and antecedents of AD. Phone calls were later done to these same subjects to fix a meeting date to interview them. Interviews were attained with $95 \%$ of effective phone calls (5\% of contacted persons refused to participate). Non-effective calls $(31 \%)$ were mostly due to incorrect phone numbers (Fig. 1).

Controls were randomly selected through Social Security registers, which in Spain cover almost $100 \%$ of the population. The aim was to have a $2: 1$ ratio of cases and controls, controls being matched to cases for gender, age at interview, and municipality of residence at interview. Matching for these variables was always accomplished in the selection of controls but the 2:1 ratio was not attained; nevertheless, all cases have at least one matched control. Eligible controls were invited by mail to participate in the research, introduced as a health study of the elderly. Eight percent of the letters were returned because of wrong or incomplete address. As with cases, phone calls were done in order to fix a date for personal interview. Twenty three percent of these calls were not valid, mostly because of incorrect number (59\%) and non-answer (29\%) after seven attempts at different times. Sixty one percent of located controls agreed to participate, and for $87 \%$ of them, the interview was completed (Fig. 1).

\section{Personal interviews}

Next-of-kin of participating cases were personally interviewed ( $n=176$ ). All controls were personally interviewed $(n=246)$ and, when possible ( $n=$ 108), independent interviews were also performed with 
(a)

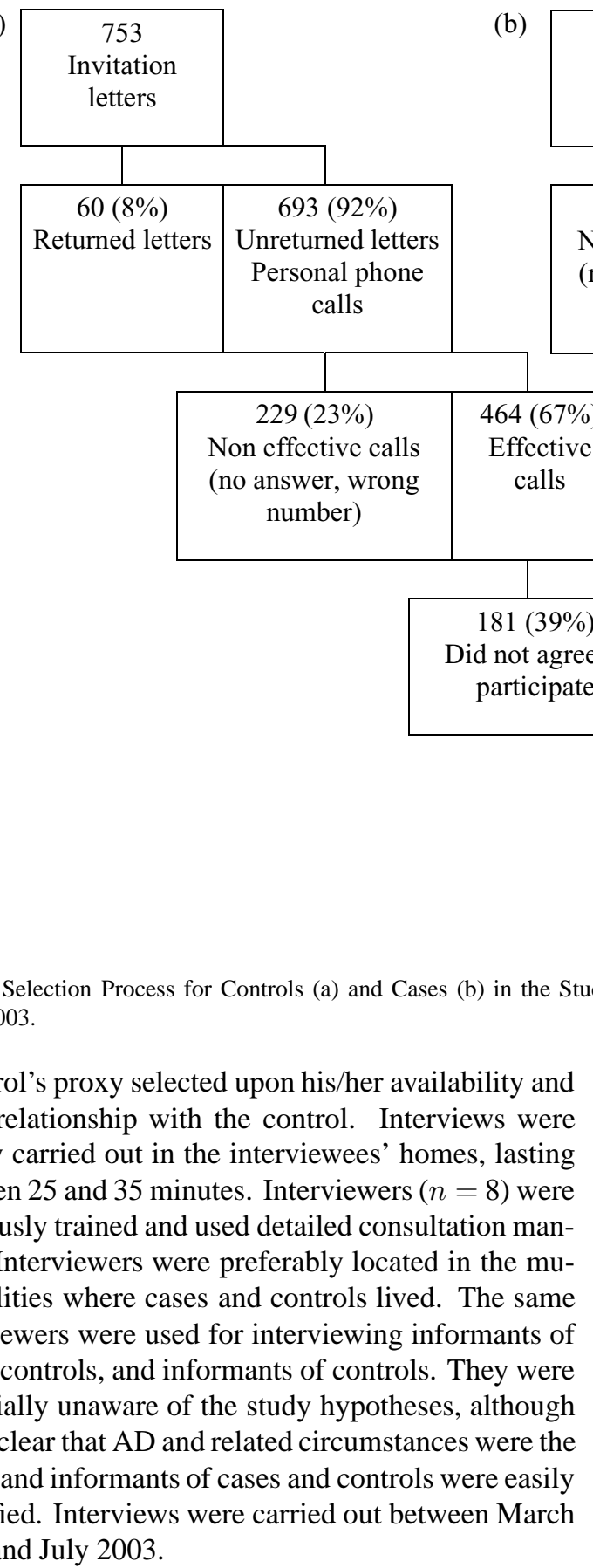

\section{Tobacco and alcohol consumption assessment}

Information in the structured questionnaire was organized in five sections: personal and family data, occupational history and exposures, lifestyles (tobacco and alcohol consumption), medical history (present and former health problems related to dementia), and social factors (education level and socioeconomic situation), all questions referring to antecedents or exposures with a potential relationship with $\mathrm{AD}$ according to available evidence. The questionnaire used in the study was previously piloted in order to test and improve its contents and structure [23].

Controls and informants of cases and controls were asked about the index subject consumption of tobacco and alcohol before the age of onset of the disease in the cases (and same reference age for their age-matched controls), including dates of starting and quitting, and average daily amounts and types of tobacco and alcoholic beverages. Average daily smoked cigarettes were considered for dose-response analysis. Information regarding amount and frequency of consumption of different categories of alcoholic beverages grouped according to alcohol content (beer, wine, and liquors) was collected and then transformed to mean daily total consumption of pure alcohol (in cubic centimetres, cc), with one unit (glass or cup) of beer or cider being equivalent to $8.5 \mathrm{cc}$ of alcohol, one unit of wine or cava being equivalent to $12 \mathrm{cc}$ of alcohol, and one unit of liquors 
being equivalent to $20 \mathrm{cc}$ of alcohol. People in the categories "Never smokers" or "Never drinkers" reported null consumption of tobacco or alcohol throughout their life, respectively.

\section{ApoE genotype ascertainment in cases}

Apolipoprotein E (ApoE) genotype was assessed using PCR on blood samples from cases whose informants agreed to this test after signing informed consent. The technique and detailed results have been presented before [24]. In statistical analyses, ApoE genotype was dichotomized into presence of one ApoE4 allele (homozygotes and heterozygotes) or absence of any ApoE4 allele (i.e., any combination of ApoE2 and ApoE3 alleles).

\section{Statistical analyses}

Univariate analyses were performed as customary. Multivariate-adjusted odds ratios (aOR) and their 95\% confidence intervals (CI) were computed through unconditional logistic regression [25]. Covariates included in the analyses were education level (categorized as less than primary education, primary education, and secondary-high education), life-long global economic situation (very good-good, and regular-bad-very bad), paid employment in the past (yes, no), history of dementia in close relatives (parents, brothers or sisters, children; yes, no), and gender, age (age at onset of the disease in cases, and same age in matched controls), and municipality of residence. Main analyses were repeated stratifying by gender, ApoE4 (presence or absence of any ApoE4 allele), and AD onset before or after 65 years (early and late onset cases, respectively). The effects of joint consumption of tobacco and alcohol were investigated too. Additional analyses were performed excluding heavy alcohol drinkers, as heavy alcohol consumption is a known cause of dementia. Tobacco analyses were also repeated excluding subjects with antecedents of hypertension, cerebrovascular disease, or arteriosclerosis. Interactions between smoking and hypertension were explored too. In a previous analysis, good correlations were found between information elicited from controls and their proxy respondents [26]. Thus, for the present analysis we only used information directly obtained from controls $(n=246)$ and from cases' informants $(n=176)$. All data analyses were performed using Stata version 9.0 software (StataCorp LP, College Station, TX).
Statistical power in our data for the main associations observed was obtained based on the number of subjects in the different categories and the observed prevalence of exposure. These calculations were performed using the Power Calculator tool for unmatched case-control studies in OpenEpi software (www.openepi.com).

\section{RESULTS}

Interviews were completed with informants of 176 cases, of whom 141 (80\%) were reported to show three main key symptoms related to AD diagnosis (cognitive impairment with gradual onset and progression, recent memory impairment, and impaired activities of daily living). ApoE genotyping was available for 113 cases $(64 \%), 60$ of whom $(53 \%)$ were carriers of at least one ApoE4 allele.

Table 1 shows the main characteristics of cases and controls. No differences were observed in gender, age, or residence. By contrast, the two groups differed in education, with more controls than cases in the upper and lower educational levels. Controls reported a better life-long economic situation than cases. Differences were also observed for depression, more frequent in cases, and for cardiovascular diseases, affecting controls with a higher frequency. Dementia in close relatives was reported more frequently in cases than controls.

Table 2 shows results for tobacco. No overall relationship was found with risk of AD. Neither were there associations seen with number of cigarettes smoked per day, number of years smoking, and time since quitting smoking before age at diagnosis. There was no evidence of interactions between tobacco and educational level, gender, familiar antecedents of dementia, or time of AD onset (data not shown). Association between smoking and AD risk was equally absent in ApoE4 carriers and non-carriers. Excluding subjects with antecedents of cardiovascular disease (hypertension, cerebrovascular disease, and/or arteriosclerosis, see Table 1) did not yield substantially different results (data not shown). Smoking cases showed slightly lower mean age at diagnosis than non-smoking cases (respectively, 67.9 and 69.8 years, 2 sided $p=0.078$ ).

A protective effect was observed for alcohol, with ever consumers showing lower risk of AD than never consumers $(\mathrm{aOR}=0.53,95 \%$ CI $0.32,0.88)$ (Table 3$)$. This association was unambiguous only for women, and all remaining analyses are stratified by gender. Mean daily total consumption of pure alcohol (cc) 
Table 1

Main Characteristics of Cases with Alzheimer's Disease $(n=176)$ and Controls $(n=246)$ when Interview was Performed. Case-Control Study on Risk Factors for Alzheimer's Disease, Spain, 2001-2003

\begin{tabular}{|c|c|c|c|}
\hline & Cases n $(\%)^{\mathrm{a}}$ & Controls $\mathrm{n}(\%)^{\mathrm{a}}$ & $\mathrm{p}^{\mathrm{b}}$ \\
\hline \multicolumn{4}{|l|}{ Gender } \\
\hline Men & $49(27.8)$ & $69(28.0)$ & \\
\hline Women & $127(72.2)$ & $177(72.0)$ & 0.963 \\
\hline \multicolumn{4}{|l|}{ Age (years) } \\
\hline$<60$ & $15(8.6)$ & $21(8.8)$ & \\
\hline $60-64$ & $22(12.6)$ & $29(12.2)$ & \\
\hline $65-69$ & $46(26.5)$ & $70(29.4)$ & \\
\hline $70-74$ & $48(27.6)$ & $57(23.9)$ & \\
\hline $75-79$ & $31(17.8)$ & $43(18.1)$ & \\
\hline$>=80$ & $12(6.9)$ & $18(7.6)$ & 0.968 \\
\hline \multicolumn{4}{|l|}{ Residence } \\
\hline Alcoy & $81(46.0)$ & $92(37.5)$ & \\
\hline Alicante & $10(5.6)$ & $21(8.6)$ & \\
\hline Elda & $36(20.5)$ & $56(22.9)$ & \\
\hline Valencia & $36(20.5)$ & $49(20.0)$ & \\
\hline Villena & $13(7.4)$ & $26(11.0)$ & 0.325 \\
\hline \multicolumn{4}{|l|}{ Education } \\
\hline$<$ Primary level & $65(36.9)$ & $129(52.4)$ & \\
\hline Primary level & $91(51.7)$ & $76(30.9)$ & \\
\hline High school-university & $20(11.4)$ & $41(16.7)$ & $<0.001$ \\
\hline \multicolumn{4}{|l|}{ Reported economic status } \\
\hline Very good - Good & $64(36.4)$ & $115(46.9)$ & \\
\hline Regular - Bad - Very bad & $112(63.6)$ & $130(53.1)$ & 0.030 \\
\hline \multicolumn{4}{|l|}{ Paid employment in the past } \\
\hline Yes & $145(82.4)$ & $204(82.9)$ & 0.885 \\
\hline \multicolumn{4}{|l|}{ Co-morbidity } \\
\hline Depression & $74(42.5)$ & $56(22.8)$ & $<0.001$ \\
\hline Parkinson's disease & $10(5.8)$ & $8(3.3)$ & 0.214 \\
\hline Hypertension & $48(27.6)$ & $107(43.7)$ & 0.001 \\
\hline Cerebrovascular disease & $29(16.7)$ & $28(11.4)$ & 0.123 \\
\hline Arteriosclerosis & $27(15.8)$ & $56(23.0)$ & 0.073 \\
\hline \multicolumn{4}{|l|}{ Dementia in close relatives } \\
\hline Yes & $79(47.6)$ & $19(7.8)$ & $<0.001$ \\
\hline
\end{tabular}

${ }^{\text {a }}$ Percentages are estimated over total of valid answers for each item.

${ }^{\mathrm{b}}$ Two sided $\mathrm{p}$ values for $\chi^{2}$ test.

showed an increasingly protective dose-relationship for women, but not for men. A strong protective association was also observed for women having drank for 40 years or more before reference age in cases and controls $(\mathrm{aOR}=0.22,95 \%$ CI $0.08,0.66)$, with evidence of dose-response relationship too. The relationship with time since quitting alcohol before reference age is uncertain (Table 3). No major differences were found among the three types of alcohol consumed (beer, wine, and liquors), or when dropping heavy drinkers ( $>20 \mathrm{cc}$ pure alcohol per day) (data not shown). Analysis considering only ApoE4 carrier cases showed only slightly stronger protective associations, mostly for women (ever vs. never consumers, both genders: $\mathrm{aOR}=0.42$, 95\% CI 0.19, 0.91; women: $\mathrm{aOR}=0.29 ; 95 \%$ CI 0.11, 0.77 ; men aOR $=0.89,95 \%$ CI 0.17, 4.55). Associations lost statistical significance in ApoE4 non-carriers, though they still pointed to the same protective effect (ever vs. never consumers, aOR $=0.67,95 \%$ CI 0.31 , 1.43; women: $\mathrm{aOR}=0.70 ; 95 \%$ CI $0.31,1.60$; men $\mathrm{aOR}=0.23,95 \%$ CI $0.03,1.76$ ). Separate analyses on early and late onset cases did not substantially vary from previous results.

Finally, interaction between tobacco and alcohol consumption was investigated. Unadjusted logistic regression model showed statistical significance for the interaction term between tobacco and alcohol ( $p=$ 0.011 ), and this interaction term was also statistically significant in the model including our potentially confounding variables $(p=0.003)$. Table 4 shows the results from adjusted analyses with the different combinations of this interaction. Although for some of the analyses the number of subjects was notably low, most consistent results across different combinations are seen for drinkers who never smoked, showing significantly reduced AD risk, both in men and women, when com- 
Table 2

Tobacco Consumption ${ }^{\mathrm{a}}$ and Risk for Alzheimer's Disease. Case-Control Study on Risk Factors for Alzheimer's Disease, Spain, 2001-2003

\begin{tabular}{lccccccc}
\hline & Cases n $(\%)$ & Controls n $(\%)$ & $\mathrm{p}^{\mathrm{b}}$ & $\mathrm{cOR}$ & $95 \%$ CI & $\mathrm{aOR}$ & $95 \%$ CI \\
\hline Smoker & & & & & & & \\
$\quad$ Never & $134(76.1)$ & $194(78.9)$ & & 1 & & 1 & \\
$\quad$ Ever & $42(23.9)$ & $52(21.1)$ & 0.507 & 1.17 & $0.74,1.86$ & 1.18 & $0.57,2.45$ \\
Cigarettes/day & & & & & & & \\
$\quad$ Non smokers & 134 & 194 & & 1 & & 1 & \\
$\quad<=10$ & $14(41.2)$ & $22(47.8)$ & & 0.92 & $0.46,1.87$ & 1.22 & $0.48,3.11$ \\
$11-20$ & $15(44.1)$ & $14(30.4)$ & & 1.55 & $0.72,3.32$ & 1.34 & $0.48,3.70$ \\
$>20$ & $5(14.7)$ & $10(21.8)$ & 0.614 & 0.72 & $0.24,2.17$ & 0.90 & $0.20,3.99$ \\
Time smoking & & & & & & & \\
Non smokers & 134 & 194 & & 1 & & 1 & \\
$<=20$ years & $7(26.9)$ & $10(23.8)$ & & 1.01 & $0.38,2.73$ & 1.66 & $0.54,5.09$ \\
21-40 years & $13(50.0)$ & $13(31.0)$ & & 1.45 & $0.65,3.22$ & 1.49 & $0.49,4.55$ \\
$>40$ years & $6(23.1)$ & $19(45.2)$ & 0.282 & 0.46 & $0.18,1.17$ & 0.62 & $0.18,2.10$ \\
Quitting time & & & & & & & \\
Non smokers & 134 & 194 & & 1 & & 1 & \\
$<=5$ years & $12(33.3)$ & $9(25.7)$ & & 1.93 & $0.79,4.71$ & 2.14 & $0.68,6.73$ \\
6-20 years & $11(30.6)$ & $15(42.9)$ & & 1.06 & $0.47,2.38$ & 1.30 & $0.45,3.77$ \\
$>$ 20 years & $13(36.1)$ & $11(31.4)$ & 0.316 & 1.71 & $0.74,3.93$ & 2.34 & $0.79,6.94$ \\
\hline
\end{tabular}

aOR: odds ratio adjusted by gender, age at diagnosis, residence municipality, education, economic status, paid employment in the past and family history of dementia; cOR: crude odds ratio; $95 \%$ CI: $95 \%$ confidence interval.

${ }^{a}$ All data on tobacco consumption are measured in the period before the age of onset of the disease in the cases (and same reference age for their age-matched controls).

${ }^{\mathrm{b}}$ Two sided $\mathrm{p}$ values for $\chi^{2}$ test.

${ }^{\mathrm{c}}$ Information on amounts and time periods smoking was not available for all smokers.

pared with subjects never drinking or smoking throughout life, independently of the presence of any ApoE4 allele in cases (information on ApoE was not available for controls).

\section{DISCUSSION}

We found that tobacco consumption did not affect risk of $\mathrm{AD}$ whereas alcohol had a protective effect, mostly in women. The lower AD risk was particularly evident among alcohol drinkers who never smoked, both in men and women, and independently of ApoE4 alleles. Regarding analyses considering ApoE4 presence in cases, it should be noticed that we had no information on ApoE alleles in controls and $p$ values are not adjusted for the potential multiple uses of data (cases carrying and not carrying ApoE4 are compared with the same subgroups of controls).

Although the low number of observations when addressing associations in some categories of exposure should be noticed, statistical power calculations with our data (based on the number of subjects and observed prevalence of exposure) was satisfactory for previously stressed main results: the power in our study to detect a significant difference for alcohol consumption between cases and controls at the significance level of $0.05(95 \%$ confidence interval) was $90 \%$ (94\% in women), and regarding the risk for ever drinkers and never smokers it reached $99 \%$.

It has been argued that joint effects of alcohol and tobacco use on $\mathrm{AD}$ can be expected as both affect brain nicotinic cholinergic receptors [21]. Our data suggest that interactions between alcohol and tobacco do exist. It is likely that inappropriate assessment of joint effects of alcohol and tobacco in previous studies could explain divergent results. For example, in aged Spanish women as those included in our sample, tobacco consumption was still unusual, while moderate alcohol consumption is more frequent. In our study more women than men were recruited. If only joint analyses were carried out, some interactions between gender and tobacco and alcohol consumption could remain blurred. Again, for some combinations of gender, tobacco and alcohol consumption our study had a low number of subjects. It would hence be interesting to assess interactions between tobacco and alcohol in large prospective studies such as the cohort of British doctors [27].

A protective effect of smoking could be due to survival bias when prevalent cases are used if smokers with AD have relatively higher mortality rates than smokers without AD [14]. Increased mortality has been ob- 
Table 3

Alcohol Consumption ${ }^{\mathrm{a}}$ and Risk for Alzheimer's Disease. Case-Control Study on Risk Factors for Alzheimer's Disease, Spain, 2001-2003

\begin{tabular}{|c|c|c|c|c|c|c|c|}
\hline & Cases n (\%) & Controls n (\%) & $\mathrm{p}^{\mathrm{b}}$ & $\mathrm{cOR}$ & $95 \% \mathrm{CI}$ & $\mathrm{aOR}$ & $95 \% \mathrm{CI}$ \\
\hline \multicolumn{8}{|l|}{ Drinker } \\
\hline \multicolumn{8}{|l|}{ Both genders } \\
\hline Never & $95(54.3)$ & $93(38.0)$ & & 1 & & 1 & \\
\hline Ever & $80(45.7)$ & $152(62.0)$ & 0.001 & 0.51 & $0.35,0.76$ & 0.53 & $0.32,0.88$ \\
\hline \multicolumn{8}{|l|}{ Women } \\
\hline Never & $84(63.1)$ & $81(45.8)$ & & 1 & & 1 & \\
\hline Ever & 43 (33.9) & $96(54.2)$ & $<0.001$ & 0.43 & $0.27,0.69$ & 0.48 & $0.27,0.84$ \\
\hline \multicolumn{8}{|l|}{ Men } \\
\hline Never & $11(22.9)$ & $12(17.7)$ & & 1 & & 1 & \\
\hline Ever & $37(77.1)$ & $56(82.3)$ & 0.483 & 0.72 & $0.29,1.80$ & 0.80 & $0.23,2.80$ \\
\hline \multicolumn{8}{|l|}{ cc alcohol/day ${ }^{\mathrm{d}}$} \\
\hline \multicolumn{8}{|l|}{ Women } \\
\hline Non drinkers & 84 & 81 & & 1 & $<0.001^{\mathrm{c}}$ & 1 & $0.005^{\mathrm{c}}$ \\
\hline$<1$ & $19(44.2)$ & $28(29.2)$ & & 0.65 & $0.34,1.26$ & 0.68 & $0.31,1.50$ \\
\hline $1-12$ & $14(32.5)$ & $38(39.6)$ & & 0.36 & $0.18,0.70$ & 0.42 & $0.19,0.94$ \\
\hline$>12$ & $10(23.3)$ & $30(31.2)$ & 0.002 & 0.32 & $0.15,0.70$ & 0.37 & $0.15,0.89$ \\
\hline \multicolumn{8}{|l|}{ Men } \\
\hline Non drinkers & 11 & 12 & & 1 & & 1 & \\
\hline$<1$ & $4(10.8)$ & $8(14.3)$ & & 0.55 & $0.13,2.33$ & 0.11 & $0.01,1.71$ \\
\hline $1-12$ & $9(24.3)$ & $15(26.8)$ & & 0.65 & $0.20,2.09$ & 0.66 & $0.13,3.36$ \\
\hline$>12$ & $24(64.9)$ & $33(58.9)$ & 0.831 & 0.79 & $0.30,2.10$ & 1.06 & $0.28,3.94$ \\
\hline \multicolumn{8}{|l|}{ Time drinking ${ }^{\mathrm{d}}$} \\
\hline \multicolumn{8}{|l|}{ Women } \\
\hline Non drinkers & 84 & 81 & & 1 & $<0.001^{\mathrm{c}}$ & 1 & $0.003^{\mathrm{c}}$ \\
\hline$<=20$ years & $3(21.4)$ & $7(14.0)$ & & 0.41 & $0.10,1.65$ & 0.33 & $0.06,1.80$ \\
\hline $21-40$ years & $6(42.9)$ & $15(30.0)$ & & 0.39 & $0.14,1.04$ & 0.48 & $0.16,1.45$ \\
\hline$>40$ years & $5(35.7)$ & $28(56.0)$ & 0.001 & 0.17 & $0.06,0.47$ & 0.22 & $0.08,0.66$ \\
\hline \multicolumn{8}{|l|}{ Men } \\
\hline Non drinkers & 11 & 12 & & 1 & & 1 & \\
\hline$<=20$ years & $1(5.6)$ & $0(0.0)$ & & - & & - & \\
\hline $21-40$ years & $8(44.4)$ & $10(26.3)$ & & 0.87 & $0.25,3.01$ & 0.42 & $0.05,3.42$ \\
\hline$>40$ years & $9(50.0)$ & $28(73.7)$ & 0.119 & 0.35 & $0.12,1.06$ & 0.47 & $0.07,2.97$ \\
\hline \multicolumn{8}{|l|}{ Quitting time $^{\mathrm{d}}$} \\
\hline \multicolumn{8}{|l|}{ Women } \\
\hline Non drinkers & 84 & 81 & & 1 & & 1 & \\
\hline$<=5$ years & $17(70.8)$ & $65(84.4)$ & & 0.25 & $0.14,0.47$ & 0.31 & $0.15,0.62$ \\
\hline $6-20$ years & $6(25.0)$ & $3(3.9)$ & & 1.93 & $0.47,7.98$ & 2.49 & $0.54,11.43$ \\
\hline$>20$ years & $1(4.2)$ & $9(11.7)$ & $<0.001$ & 0.11 & $0.01,0.86$ & 0.10 & $0.01,1.01$ \\
\hline \multicolumn{8}{|l|}{ Men } \\
\hline Non drinkers & 11 & 12 & & 1 & & 1 & \\
\hline$<=5$ years & $17(68.0)$ & 47 (88.7) & & 0.39 & $0.15,1.06$ & 0.40 & $0.10,1.55$ \\
\hline $6-20$ years & $7(28.0)$ & $4(7.5)$ & & 1.91 & $0.44,8.35$ & 0.96 & $0.12,7.59$ \\
\hline$>20$ years & $1(4.0)$ & $2(3.8)$ & 0.056 & 0.55 & $0.04,6.89$ & 1.05 & $0.06,18.30$ \\
\hline
\end{tabular}

aOR: odds ratio adjusted by gender (only in analysis for both genders), age at diagnosis, residence municipality, education, economic status, paid employment in the past and family history of dementia; cOR: crude odds ratio; c 95\% CI: $95 \%$ confidence interval.

${ }^{a}$ All data on alcohol consumption are measured in the period before the age of onset of the disease in the cases (and same reference age for their age-matched controls).

${ }^{\mathrm{b}}$ Two sided $\mathrm{p}$ values for $\chi^{2}$ test.

${ }^{\mathrm{c}}$ Two sided $\mathrm{p}$ value for trend.

${ }^{\mathrm{d}}$ Information on amounts and time periods drinking was not available for all drinkers.

served among smokers with dementia [28]. Besides, smoking could appear as a protective exposure if it delays onset of the disease [1]. However, in a sample of patients with $\mathrm{AD}$ followed to autopsy, active smokers were significantly younger at onset of $\mathrm{AD}$ and also sig- nificantly younger at death than never smokers [29]. In our data mean age at disease onset was slightly lower in smoking than in non-smoking cases, a result also reported in other studies [1]. Our analysis of tobacco consumption considering available information on pre- 
Table 4

Risk for Alzheimer's Disease in Different Subgroups According to Alcohol and Tobacco Consumption ${ }^{\mathrm{a}}$. CaseControl Study on Risk Factors for Alzheimer's Disease, Spain, 2001-2003

\begin{tabular}{|c|c|c|c|c|c|}
\hline & Cases n (\%) & Controls n $(\%)$ & $\mathrm{p}^{\mathrm{b}}$ & $\mathrm{aOR}$ & $95 \% \mathrm{CI}$ \\
\hline \multicolumn{6}{|l|}{ All } \\
\hline Never smoker and never drinker & $90(51.4)$ & $83(33.9)$ & & 1 & \\
\hline Ever smoker, never drinker & $5(2.9)$ & $10(4.1)$ & & 0.21 & $0.05,0.98$ \\
\hline Ever drinker, never smoker & $43(24.6)$ & $111(45.3)$ & & 0.37 & $0.21,0.65$ \\
\hline Ever smoker and drinker & $37(21.1)$ & $41(16.7)$ & $<0.001$ & 0.85 & $0.36,1.98$ \\
\hline \multicolumn{6}{|l|}{ Men } \\
\hline Never smoker and never drinker & $7(14.6)$ & $4(5.9)$ & & 1 & \\
\hline Ever smoker, never drinker & $4(8.3)$ & $8(11.7)$ & & 0.04 & $0.002,0.70$ \\
\hline Ever drinker, never smoker & $8(16.7)$ & $21(30.9)$ & & 0.12 & $0.02,0.79$ \\
\hline Ever smoker and drinker & $29(60.4)$ & $35(51.5)$ & 0.154 & 0.26 & $0.05,1.43$ \\
\hline \multicolumn{6}{|l|}{ Women } \\
\hline Never smoker and never drinker & $83(65.3)$ & $79(44.6)$ & & 1 & \\
\hline Ever smoker, never drinker & $1(0.8)$ & $2(1.1)$ & & 0.22 & $0.01,3.38$ \\
\hline Ever drinker, never smoker & $35(27.6)$ & $90(50.9)$ & & 0.39 & $0.22,0.71$ \\
\hline Ever smoker and drinker & $8(6.3)$ & $6(3.4)$ & 0.001 & 1.95 & $0.51,7.44$ \\
\hline \multicolumn{6}{|c|}{ Only cases with at least one ApoE4 allele } \\
\hline Never smoker and never drinker & $33(55.0)$ & $83(33.9)$ & & 1 & \\
\hline Ever smoker, never drinker & $2(3.3)$ & $10(4.1)$ & & 0.32 & $0.05,1.86$ \\
\hline Ever drinker, never smoker & $11(18.3)$ & $111(45.3)$ & & 0.24 & $0.11,0.52$ \\
\hline Ever smoker and drinker & $14(23.4)$ & $41(16.7)$ & 0.172 & 0.59 & $0.19,1.85$ \\
\hline \multicolumn{6}{|c|}{ Only cases without any ApoE4 allele } \\
\hline Never smoker and never drinker & $23(44.2)$ & $83(33.9)$ & & 1 & \\
\hline Ever smoker, never drinker & $2(3.8)$ & $10(4.1)$ & & 0.62 & $0.10,3.72$ \\
\hline Ever drinker, never smoker & $15(28.9)$ & $111(45.3)$ & & 0.49 & $0.24,1.03$ \\
\hline Ever smoker and drinker & $12(23.1)$ & $41(16.7)$ & 0.001 & 0.91 & $0.29,2.85$ \\
\hline
\end{tabular}

aOR: odds ratio adjusted by gender (except for analysis by gender), age at diagnosis, residence municipality, education, economic status, paid employment in the past and familial antecedents of dementia (except for analysis by ApoE4 allele); 95\% CI: 95\% confidence intervals.

a All data on tobacco and alcohol consumption are measured in the period before the age of onset of the disease in the cases (and same reference age for their age-matched controls).

${ }^{\mathrm{b}}$ Two sided $\mathrm{p}$ values for $\chi^{2}$ test.

${ }^{\mathrm{c}}$ ApoE genotype was available for 113 cases (60 ApoE4 carriers and 53 ApoE4 non carriers). Information on ApoE was not available for controls. $\mathrm{P}$ values are not adjusted for the potential multiple uses of data (cases carrying and not carrying ApoE4 are here compared with the same controls in each category).

viously suggested potential effect modifiers (duration and intensity of smoking, time since last smoking, age of onset of the disease, and ApoE4 allele) did not yield substantially different results.

Our results for alcohol consumption generally pointed to a protective effect, mostly for lifelong drinking women. Women in our sample were mainly light or moderate consumers (only four controls and one case reported to drink more than $20 \mathrm{cc}$ alcohol/day). Few previous studies on alcohol and AD stratified by gender (adjusting by gender has been more usual). Again, different patterns of alcohol consumption by gender, and interaction with tobacco consumption could determine variability in the results found in different studies. Nonetheless, a protective effect of moderate alcohol consumption has been frequently reported [17-19]. Different effects according to type of alcohol beverages have also been reported, and it has been proposed that resveratrol, found in wine but not in other alcoholic beverages, could be responsible [17]. Our data allowed analysis considering consumption of three main categories of beverages (beer, wine, and liquors) but no differences were observed: as compared to non-drinkers, similar protective effects for consumers of the three beverages were observed. We observed protective effects mostly for women with low alcohol consumption. Beneficial vascular effects of moderate drinking could be related to the potential protective effect of alcohol use on AD [30]. Also, moderate alcohol intake might favorably alter release of acetylcholine in the brain [31]. Antioxidant effects of alcohol, and particularly of wine, have also been proposed as potential mechanisms [18]. Again, survival bias could explain a protective effect of alcohol for dementia in prevalent cases. Yet, to the extent that all the analyses are referred to alcohol consumption before the age of disease onset, this potential bias should be minimized in our results.

Although the strong association between ApoE4 alleles and increased risk of $\mathrm{AD}$ is indisputable, the spe- 
cific etiopathogenic role of ApoE4 is under discussion [32]. There is a clear need to further analyze interactions between environmental exposures and ApoE4 genotypes. In our analyses, the inclusion of cases with and without an ApoE4 allele did not substantially alter any of the results.

Some limitations of this study and their potential effects in observed results should be recognized. Our cases are not a representative sample of all people suffering from $\mathrm{AD}$, but a selected sample of those reaching local Alzheimer's Disease Associations (ADAs). Medical record verification of diagnoses was not possible, and although medical diagnosis of $\mathrm{AD}$ is required for registration in an ADA and diagnosis was verified in the interviews with close relatives, some misclassification of disease in cases is possible, and, to an even lesser extent, it cannot be fully discarded for very early stages of the disease among controls. This problem commonly affects epidemiological studies of $\mathrm{AD}$, as far as only autopsy is considered the gold standard for diagnosis of many dementias [33]. However, if some cases with other diseases than AD (most probably other dementias) are included in our sample of cases, and cases of AD (or other dementias at very early stages of evolution) are included in our sample of controls, and the associations with tobacco and alcohol consumption found in this study are real, this disease classification bias most probably would affect diluting observed associations.

All information on exposures was elicited using a questionnaire. Controls answered about their life-long tobacco and alcohol consumption, while proxies gave this same information for cases. If informants of cases reported real exposures in cases with a lesser frequency than controls did for their own exposures, a false protective effect could have occurred. Conversely, the effect of a potential recall bias among informants of cases would be a higher frequency of exposure reporting in cases than in controls, and spurious increased risks would then ensue. We are not able to check potential biases due to the retrospective nature of our study and to the use of informants for cases. We were only able to compare reports of exposure in informants of controls and controls themselves in a previous analysis [26]. For qualitative estimates of consumption of tobacco and alcohol, concordance indices between controls and their informants were generally high $(>0.6$, good-very good). However, lower concordance items were obtained for quantitative estimates addressing mainly the amount of alcohol or tobacco consumed in the past. This uncertainty on quantitative information could perhaps explain our non consistent results in analyses on dose-response relationships.
Regarding selection bias, with the potential of distorting the distribution of variables of interest in the sample of cases and controls being compared, although most of located cases' informants agreed to participate (Fig. 1), 47\% eligible and located controls refused. We did not have access to relevant information for nonparticipants, so a comparison between participants and non-participants was not possible. If tobacco or alcohol consumption is differently related to likelihood to participate in controls and cases, our results may have been altered in any direction. Besides, highly educated controls are more likely to participate, although more cases than controls completed primary level education. Tobacco and alcohol consumption could present different distributions in groups of people with different education level. But in adjusted analysis we always controlled by education and, more importantly, no major differences were found between crude and adjusted estimates.

With previous considerations in mind, we believe that our results add to existing evidence on the association between AD and tobacco and alcohol consumption, and strongly suggest the need to consider interactions between both exposures, as well as interactions with gender, to further clarify their effects on the risk of $\mathrm{AD}$ and the still largely unknown relationship of environmental factors with this disease.

\section{ACKNOWLEDGMENTS}

This work was partially supported by the Fondo de Investigaciones Sanitarias, Ministry of Health, Spain [grant number 00/0811]; Consellería de Sanitat de la Generalitat Valenciana, Valencia, Spain [grant numbers EVES2001-018 and EVES2003-PI-028]; and CIBER de Epidemiología y Salud Pública (CIBERE$S P)$, Instituto de Salud Carlos III, Spain. The support of Pablo Peñataro, Miguel Santibáñez, and Mercedes Aler during field work is greatly appreciated.

Authors' disclosures available online (http://www.jalz.com/disclosures/view.php?id=287).

\section{REFERENCES}

[1] Graves AB, Van Duijn CM, Chandra V, Fratiglioni L, Heyman A, Jorm AF, Kokmen E, Kondo K, Mortimer JA, Rocca WA (1991) Alcohol and tobacco consumption as risk factors for Alzheimer's disease: a collaborative re-analysis of case-control studies. Int J Epidemiol 20(Suppl 2), S48-S57. 
[2] Lee PN (1994) Smoking and Alzheimer disease: a review of recent epidemiological evidence. Neuroepidemiol 13, 131144.

[3] Prince M, Cullen M, Mann A (1994) Risk factors for Alzheimer's disease and dementia: a case-control study based on the MRC elderly hypertension trial. Neurology 44, 97-104.

[4] Ott A, Slooter AJC, Hofman A, van Harskamp F, Witteman JCM, van Broeckhoven C, van Duijn CM, Breteler MM (1998) Smoking and risk of dementia and Alzheimer's disease in a population-based cohort study, the Rotterdam study. Lancet 351, 1840-1843.

[5] Merchant C, Tang MX, Albert S, Manly J, Stern Y, Mayeux $\mathrm{R}$ (1999) The influence of smoking on the risk of Alzheimer's disease. Neurology 52, 1408-1412.

[6] Launer LJ, Andersen K, Dewey ME, Letenneur L, Ott A, Amaducci LA, Brayne C, Copeland JR, Dartigues JF, KraghSorensen P, Lobo A, Martinez-Lage JM, Stijnen T, Hofman A (1999) Rates and risk factors for dementia and Alzheimer's disease. Neurology 52, 78-84.

[7] Reitz C, den Heijer T, van Duijn C, Hofman A, Breteler MMB (2007) Relation between smoking and risk of dementia and Alzheimer disease. Neurology 69, 998-1005.

[8] Van Duijn CM, Havekes LM, Van Broeckhoven C, de Knijff P, Hofman A (1995) Apolipoprotein E genotyppe and association between smoking and early onset Alzheimer's disease. BMJ 310, 627-631.

[9] Brenner DE, Kukull WA, van Belle G, Bowen JD, McCromick WC, Teri L, Larson EB (1993) Relationship between cigarette smoking and Alzheimer's disease in a population based casecontrol study. Neurology 43, 293-300.

[10] Wang PN, Wang SJ, Hong CJ, Liu TT, Fuh JL, Chi CW, Liu CY, Liu HC (1997) Risk factors for Alzheimer's disease, a case-control study. Neuroepidemiol 16, 234-240.

[11] Aggarwal NT, Bienias JL, Bennett DA, Wilson RS, Morris MC, Schneider JA, Shah RC, Evans DA (2006) The relation of cigarette smoking to incident Alzheimer's disease in a biracial urban community population. Neuroepidemiol 26, 140-146.

[12] Brayne C (2000) Smoking and the brain. BMJ 320, 1087-1088.

[13] Kukull WA (2001) The association between smoking and Alzheimer's disease, effects of study design and bias. Biol Psychiatry 49, 194-199.

[14] Almeida OP, Hulse GK, Lawrence D, Flicker L (2002) Smoking as a risk factor for Alzheimer's disease, contrasting evidence from systematic review of case-control and cohort studies. Addiction 97, 15-28.

[15] Hebert JE, Scherr PA, Beckett LA, Funkenstein HH, Albert CS, Chown MJ, Evans DA (1992) Relation of smoking and alcohol consumption to incident Alzheimer's disease. Am J Epidemiol 135, 347-355.

[16] Leibovici D, Ritchie K, Ledésert B, Touchon J (1999) The effects of wine and tobacco consumption on cognitive performance in the elderly. A longitudinal study of relative risk. Int $J$ Epidemiol 28, 77-81.

[17] Lindsay J, Laurin D, Verreault R, Hébert R, Hellwell B, Hil
GB, McDowel I (2002) Risk factors for Alzheimer's Disease: a prospective analysis from the Canadian Study of Health and Aging. Am J Epidemiol 156, 445-453.

[18] Luchsinger JA, Tang MX, Siddiqui M, Shea S, Mayeux R (2004) Alcohol intake and risk of dementia. J Am Geriatr Soc 52, 540-546.

[19] Ruitenberg A, van Swieten J, Witteman JCM, Mehta KM, van Duijn C, Hofman A, Breteler MMB (2002) Alcohol consumption and risk of dementia: the Rotterdam Study. Lancet 359, 281-286.

[20] Fratiglioni L, Ahlbom A, Viitanen M, Winbald B (1993) Risk factors for late-onset Alzheimer's disease: a population-based case-control study. Ann Neurol 33, 258-266.

[21] Tyas SL (2001) Alcohol use and the risk of developing Alzheimer's disease. Alcohol Res Health 25, 299-306.

[22] Asociación Nacional del Alzheimer [Spanish National Association of Alzheimer] Home page [Internet], http://www.afal.es, Accessed July 31, 2009.

[23] García AM, Pallardó R, Peñataro P, Aler M, Suay L, Verdú V (2001) Resultados del estudio piloto del proyecto EXPLABALZ (Factores de riesgo laborales en la enfermedad de Alzheimer) [Results from the project EXPLAB-ALZ (Occupational risk factors in Alzheimer's disease) pilot study]. Gac Sanit 15(Suppl 2), 56.

[24] García AM, Aler M, Suay L, Santibáñez M (2003) Polimorfismos de la apolipoproteina E en enfermos de Alzheimer de la Comunidad Valenciana (España) [Apolipoprotein E polymorphisms in Alzheimer's disease patients from Comunidad Valenciana (Spain)]. Gac Sanit 17(Suppl 2), 76.

[25] Rothman KJ, Greenland S, Lash TL (2008) Modern epidemiology. Lippincott Willian \& Wilkins, Philadelphia.

[26] Villanueva V, García AM (2006) Validity and reliability of surrogate information for controls in a case-control study on Alzheimer's disease. J Alzheimers Dis 10, 409-416.

[27] Doll R, Peto R, Boreham J, Sutherland I (2000) Smoking and dementia in male British doctors, prospective study. BMJ 320, 1097-1102.

[28] Wang HX, Fratiglioni L, Frisoni GB, Viitanen M, Winblad B (1999) Smoking and the occurrence of Alzheimer's disease, cross-sectional and longitudinal data in a population-based study. Am J Epidemiol 149, 640-644.

[29] Sabbagh MN, Tyas SL, Emery SC, Hansen LA, Alford MF, Reid RT, Tiraboschi P, Thal LJ (2005) Smoking affects the phenotype of Alzheimer disease. Neurology 64, 1301-1303.

[30] Tyas SL, Pederson LL, Koval JJ (2000) Is smoking associated with the risk of developing Alzheimer's disease? Results from three Canadian data sets. Ann Epidemiol 10, 409-416.

[31] Stampfer MJ (2006) Cardiovascular disease and Alzheimer's disease, common links. J Int Med 260, 211-223.

[32] De Kniff P, van Duijn C (1998) Role of APOE in dementia, a critical reappraisal. Haemostasis 28, 195-201.

[33] Kukull WA, Bowen JD (2002) Dementia epidemiology. Med Clin N Am 86, 573-590. 